\title{
ESTRUTURA ORGANIZACIONAL E A FORMAÇÃO EDUCACIONAL DOS TRABALHADORES DO INSTITUTO EUVALDO LODI DE MINAS GERAIS
}

\author{
ESTRUCTURA ORGANIZACIONAL Y CAPACITACION \\ DE LA EDUCACIÓN DE LOSTRABAJADORES DE LO \\ INSTITUTO EUVALDO LODI DE MINAS GERAIS
}

Janete Fernandes Silva*

\begin{abstract}
RESUMO:
Introdução: No mercado cada dia mais competitivo, que sofre com as grandes transformações, tem exigido das organizações ajustes nas suas estruturas internas, como também, melhor qualificação e formação educacional do trabalhador, estimulando-o a reflexão e a criatividade. Estas transformações forçam as organizações a agirem no aumento da produção e na oferta de resultados mais eficazes que permitam estruturas mais competitivas e inovadoras.
\end{abstract}

Objetivo: Este artigo tem como objetivo conhecer a estrutura organizacional do Instituto Euvaldo Lodi de Minas Gerais (IEL/MG) e o nível de formação educacional dos seus trabalhadores.

Metodologia: Quanto ao parâmetro metodológico utilizou-se o estudo de caso, a abordagem qualitativa e a adoção da entrevista semiestruturada. A amostra foi constituída com $100 \%$ dos gerentes sediados na cidade de Belo Horizonte e um coordenador na linha de staff do Instituto. Os encontros foram agendados previamente e as entrevistas integralmente gravadas e transcritas.

Resultados: Como principal resultado, o Instituto possui gerências que estão organizadas para ajudar na ampliação da competitividade das indústrias mineiras e na busca de fortalecer as relações entre os atores tecnológicos. Observou-se que quanto maior a atuação em mercados complexos, dinâmicos e vulneráveis, maior a exigência por serviços e produtos com valor agregado, e indivíduos com formação multidisciplinares, com alto nível de formação educacional.

Conclusões: Conclui-se que a estrutura organizacional do IEL/MG está em consonância com sua meta. As áreas mais sólidas são as gerências de Inteligência Estratégica, de Inovação e de Estágio Empresarial por fazerem parte do ambiente organizacional há mais tempo. A gerência de Estudos Economia está solta na estrutura do IEL e o melhor vínculo seria próximo da presidência da FIEMG; a gerência de Capacitação Empresarial não tem com clareza o que será a sua área,

* Doutora em Educação. Professora do curso de biblioteconomia. E-mail: janetefernandes1000@gmail.com 
quais os produtos e os serviços que serão o portfólio e quais os perfis profissionais que serão necessários para a realização das atividades por ser a área mais nova no Instituto; para a gerência Centro Internacional de Negócios não importa onde a gerência esteja hierarquicamente subordinada, é preciso de infraestrutura que facilitem a implementação das atividades e que o cliente interno ou externo tenha suas necessidades e demandas atendidas.

Palavras-chave: Formação educacional. Organização. Estrutura organizacional.

\section{INTRODUÇÃO}

As organizações nas últimas duas décadas sofreram grandes transformações devido as fortes concorrências e a dinâmica econômica. Para sobreviverem nesse mercado acirrado e de constantes mudanças, elas precisaram ajustar suas estruturas internas, foi preciso rever o planejamento estratégico, o layout, o organograma, as normas, os manuais e melhorar a formação e a qualificação dos trabalhadores. Por meio da adaptação e da redefinição, elas passaram a agir no aumento da produção e na oferta de resultados mais eficazes que permitissem estruturas mais competitivas e inovadoras.

A estrutura organizacional é resultante da identificação, da análise, de ordenação, de agrupamento das atividades e dos recursos da empresa, incluindo o estabelecimento dos níveis estratégicos, gerenciais e operacionais e dos processos decisórios, na busca de alcançar os objetivos determinados no planejamento. Cabe sinalizar, que esse tipo de estrutura tende a ser dinâmica quando considera também os aspectos informais, provenientes da caracterização dos indivíduos que contribuem para manutenção do seu funcionamento (OLIVEIRA, 2009, p.69).

Partindo do pressuposto que as organizações precisam se manter inovadoras e competitivas, é necessário que essas possuam no seu quadro de trabalhadores profissionais reflexivos e criativos. Para tal, é preciso de investimentos em ensino-aprendizado e de indivíduos estimulados à formação continuada e que aumentem suas qualificações. É disto, portanto, que será tratado neste artigo: o nível educacional dos trabalhadores que estão inseridos numa estrutura organizacional que mescla arranjos de departamentalização 
funcional, mas possui características de projeto, considerada como estrutura mista.

Desta forma, esta pesquisa teve como objetivo principal conhecer a estrutura organizacional do Instituto Euvaldo Lodi de Minas Gerais (IEL/MG) e o nível de formação educacional dos seus trabalhadores. Com tal intento, buscou-se responder as seguintes perguntas: qual a formação educacional dos gerentes e funcionários do Instituto? Qual a experiência profissional dos gerentes? Como está estruturado organizacionalmente o IEL/MG? Qual a relação formação educacional e profissional com a estrutura e funções das gerências?

Para a realização da investigação, foram entrevistados seis gerentes, adotou-se o estudo de caso, a abordagem qualitativa, a ferramenta de coleta de dados foi a semiestruturada, e como resultado conclui-se que o Instituto possui uma boa infraestrutura física e de pessoal, sendo que este último é formado com aproximadamente $68 \%$ de indivíduos com nível superior.

\section{METODOLOGIA}

Para o delineamento da investigação, adotou-se o estudo de caso como estratégia de pesquisa. Priorizou-se a natureza qualitativa por permitir um melhor entendimento dos fenômenos investigados. Portanto, o fenômeno foi relatado de forma descritiva, por ter sido estudado na sua situação natural e real, tendo um plano aberto e flexível - semiestruturado - e focalizou-se a realidade de forma complexa e contextualizada. Assim, a adoção da fenomenologia pareceu ser a mais adequada, permitindo examinar todos os conteúdos enquanto dados puros e correlacioná-los através de uma construção intencional. Sua contribuição possibilitou a descrição do que foi mostrado in loco durante o levantamento dos dados.

Quanto ao instrumento de coleta de dados não se teve a intenção de apresentar perguntas preestabelecidas, mas questões a serem exploradas e que permitissem levantar as relações estabelecidas com 0 interlocutor/entrevistado. A entrevista, por ser de natureza interativa, permitiu tratar os temas complexos que dificilmente poderiam ser investigados 
adequadamente através de questionários com respostas dirigidas, explorandoos em profundidade.

A caracterização da população e da amostra está definida da seguinte forma: entrevista realizada com seis gerentes, correspondendo ao universo de $100 \%$ de gerentes sediados na cidade de Belo Horizonte e um coordenador na linha de staff do IEL/MG. O protocolo de campo ocorreu com encontros pessoais e individuais com cada um dos entrevistados e com agendamento prévio. Todas as entrevistas foram integralmente gravadas e transcritas. $O$ perfil dos entrevistados está definido na quadro 1.

\begin{tabular}{|c|c|}
\hline \multicolumn{2}{|r|}{ Quadro 01 - Perfil dos Gerentes } \\
\hline GERENTE & PERFIL \\
\hline Entrevistado 01 & $\begin{array}{l}\text { Graduado em engenharia elétrica e mestrado em ciências da computação, } \\
\text { responsável pela Gerência de Inteligência Estratégica, tem nove anos de } \\
\text { IEL/MG, com experiência profissional no Setor de telecomunicações - Telemig } \\
\text { (engenharia de tráfegos, sistema de informação e sistemas de projetos de } \\
\text { rede em telecomunicações); implementação do centro de gerência de rede do } \\
\text { Banco do Brasil; participação no projeto de integração dos sistemas de } \\
\text { engenharia da Telemar. Coordenador do projeto da RETEC; assumiu a } \\
\text { Gerência de Informação Estratégica em } 2003 \text { e é responsável pelos } \\
\text { programas de inteligência estratégica no IEL. }\end{array}$ \\
\hline Entrevistado 02 & $\begin{array}{l}\text { Graduado em economia e mestrando em gestão de inovação e } \\
\text { biofarmacêutica, responsável pela Gerência de Inovação, tem sete anos de } \\
\text { IEL/MG, experiência profissional no IEL. Iniciou como estagiário, depois foi } \\
\text { contratado pela gerência de desenvolvimento regional da indústria e assumiu } \\
\text { em } 2008 \text { a gerência de inovação. }\end{array}$ \\
\hline Entrevistado 03 & $\begin{array}{l}\text { Graduado em economia e especialização em comércio exterior - análise } \\
\text { econômica e relações internacionais -, responsável pelo Centro Internacional } \\
\text { de Negócio, dois anos de IEL/MG e vinte e cinco anos de Federação das } \\
\text { Indústrias do Estado de Minas Gerais, com experiência profissional em } \\
\text { comércio e acordo internacional e análise econômica. }\end{array}$ \\
\hline Entrevistado 04 & $\begin{array}{l}\text { Graduado em economia e especialista em economia industrial, finanças, e } \\
\text { mestrado em economia, responsável pela Gerência de Estudos Econômicos, } \\
\text { tem um ano e seis meses de IEL/MG e vinte anos de Federação das } \\
\text { Indústrias do Estado de Minas Gerais, com experiência profissional em } \\
\text { capitalização e financiamentos, análise de viabilidade de investimento em } \\
\text { negócio. }\end{array}$ \\
\hline Entrevistado 05 & $\begin{array}{l}\text { Graduado em psicologia e especialização em gestão de negócios; em gestão } \\
\text { de processos educativos; em gestão e tecnologia da qualidade; e gestão em } \\
\text { instituições educacionais, responde pela Gerência de Capacitação } \\
\text { Empresarial, tem um ano de IEL/MG, com experiência profissional em } \\
\text { recrutamento, seleção e treinamento; educação hospitalar; educação - } \\
\text { programas e sistema de qualidade. }\end{array}$ \\
\hline Entrevistado 06 & $\begin{array}{l}\text { Graduado em jornalismo, responde pela Gerência de Estágio Empresarial, tem } \\
\text { quatro anos de IEL/MG, com experiência profissional na iniciativa privada. }\end{array}$ \\
\hline Entrevistado 07 & $\begin{array}{l}\text { aduado em administração, com especialização em gestão de projetos e } \\
\text { n gestão de finanças e controladoria, responde pela coordenação do } \\
\text { cleo de Apoio à Gestão, tem nove anos de IEL/MG, com experiência em } \\
\text { tãa de projetos e controle orçamentário. }\end{array}$ \\
\hline
\end{tabular}

Fonte: Dados da pesquisa e elaboração da autora, 2013. 
Frisa-se que o quadro de colaboradores do Instituto está formado por 114 indivíduos, entre efetivos, bolsistas, consultores e estagiários.

\section{ESTRUTURA ORGANIZACIONAL E FORMAÇÃO EDUCACIONAL DOS TRABALHADORES}

O termo estrutura, mesmo no século XXI, está associado a algo físico e estático, envolto por discussões de como a vida social é delimitada ou arranjada por padrões de comportamento consolidados e contínuos que permanecem por longo tempo e que não abordam a maneira como eles se modificam ao longo do tempo.

$\mathrm{Na}$ sociedade moderna, as normas de racionalidade tomaram-se um conjunto estabelecido, sendo uma concepção socialmente construída sobre o modo eficaz de funcionamento organizacional. Como efeito, as organizações modernas são mantidas por sistemas de crenças que reforçam a permanência da racionalidade (RODRIGUES, 2008), são as organizações caracterizadas pelo tipo ideal.

Para Coelho; Coelho (2003, p.146) não se pode ignorar o papel dos indivíduos e das suas estratégias na escolha de um desenho estrutural. $O$ processo de mudança organizacional não pode ser isolado das ações e das preferências individuais, das opções de quem detém o poder. É a conciliação do pragmatismo do ponto de vista contingente com o relativismo. Trata-se igualmente de não isolar o fenômeno organizacional das circunstâncias em que se produz, dando uma especial relevância aos aspectos sociais, políticos ou culturais em que está integrado. Apesar de isso limitar as suas possibilidades de generalização, e de por um ponto final no seu pretenso universalismo, a mudança organizacional só pode ser entendida no quadro geográfico e cultural em que se concretiza (COELHO; COELHO, 2003, p.146).

No posicionamento de Machado-da-Silva; Fonseca (2010, p. 2) a natureza dos procedimentos da organização "[...] depende, além de outros fatores, de um sistema de crenças e valores e das relações de trabalho sobre ele desenvolvidos em função de elementos legitimados interna e extremamente". Para os autores as camadas sociais contribuem para a criação 
e a divulgação de novos mitos racionais. Mudanças que provocam, portanto, alterações nas rotinas organizacionais.

Acredita-se que as organizações coexistem mediante a incorporação de orientações previamente definidas e racionalizadas na sociedade, que contribuem para a legitimação de suas atividades e para sua sobrevivência, independente da eficácia e da necessidade de sua produção. Muitos programas, como os de tecnologia e de políticas, são adotados nas organizações por força de orientações contextuais, como manifestações de regras e de significados, fixados em estruturas construídas e institucionalizadas na sociedade. Desse modo, perante a incerteza ambiental, para Machado-daSilva; Fonseca (2010, p.2) "a competição entre as organizações volta-se não apenas para recursos e consumidores, como também para a legitimidade institucional, tornando suas práticas cada vez mais homogêneas dentro de um determinado domínio organizacional". Os autores sinalizam que esse efeito de modificar-se conforme as características ambientais decorrem de mecanismos coercitivos e normativos, acarretando uma homogeneização das ações de organizações pertencentes a um mesmo campo organizacional.

Na visão de Coelho; Coelho (2003, p.147) as estruturas acontecem por meio de práticas sociais que são definidas ou ocorrem segundo padrões de regularidade ou de expectativas recíprocas entre atores sociais. Tem-se 0 contexto em que a ação e a estrutura acontecem em espaço e tempo que as envolvem. Para compreender processos de estruturação é necessário entender como indivíduos pensam o tempo e o espaço em que estão inseridos e como articulam tal concepção com suas ações, agindo de acordo com o contexto cultural (O'DWYER; MATTOS, 2010).

Portanto, é preciso que os envolvidos na ação, ou atores sociais, sejam conscientes e conhecedores de suas práticas, mesmo que elas resultem em consequências inesperadas ou não planejadas. É necessário atentar que a estrutura não existe fora ou independentemente do conhecimento que os trabalhadores têm de suas atividades cotidianas (RODRIGUES, 2008). Entretanto, a organização é uma unidade social, de troca e de inter-relações. $O$ espaço organizacional passa, então, a ser aceito como um conjunto de formas 
representadas pelas relações inter e extra ambiente, ou por uma estrutura representada pelas relações sociais que se manifestam por meio de processos e de funções.

Neste estudo, serão abordadas as estruturas por projeto e por função. A primeira, estrutura por projeto, tem como característica a temporalidade, em que as atividades e as pessoas recebem atribuições temporárias. Os indivíduos envolvidos nessa estrutura possuem alta qualificação técnica em virtude das exigências dos projetos, têm liberdade funcional extremamente elevada, flexibilidade na jornada de trabalho e escolha do ambiente em que desejam executar suas atividades. A segunda, estrutura por função, é compreendida por uma estrutura que possui uma chefia para cada função, de modo que os subordinados executem mais de uma função, podendo ficar sob o comando de mais de um coordenador. Esta organizar-se de acordo com os tipos de recursos técnicos - os objetivos, as necessidades de especialização -, e os níveis de execução que se subordinam aos correspondentes níveis de comando funcional (ARAUJO, 2009, p.158).

Ambas estruturas por projeto e por função requerem qualificação e formação educacional dos trabalhadores. Entende-se neste estudo por formação educacional, os processos educativos que proporcionam aos indivíduos aprendizagem-ensino, aquisição de informações e desenvolvimento de conhecimentos conceituais, técnicos e operacionais que podem estar relacionados ao cotidiano do indivíduo e com a produção de bens e de serviços, que sejam desenvolvidos nas instituições de ensino e ou no ambiente das organizações.

A formação educacional tem como papel, também, a formação de indivíduos para o mercado de trabalho, transforma os indivíduos "reféns" das estratégias de qualidade e produtividade das organizações e das intempéries do mercado de trabalho. Deluiz (2001) sinaliza o fato de a organização apropriar-se das competências dos trabalhadores, dos saberes, dos talentos, da capacidade de inovar, da criatividade e da autonomia, esta, necessariamente, não se compromete com os processos de formação/construção dessas competências. Atribuindo, exclusivamente, aos 
trabalhadores a responsabilidade de atualização, qualificação, capacitação e nos custeios dessa formação. Não se pode desconsiderar que quanto maior a formação educacional, maior a possibilidade de o trabalhador ver seus conhecimentos serem aplicados e reconhecidos, e maiores chances de alcançar fatias de mercados favoráveis.

A formação educacional e profissional tem sido tema de debates desde a constituição do período industrial. Os aspectos no entorno desse tema tem sido acompanhada pelas constantes mudanças ocorridas no mercado de trabalho. Transformações que têm promovido diversas investigações voltadas às relações entre trabalho, qualificação e educação. Assim, os modelos de qualidade, as novas tecnologias e os programas de competência passaram a configurar-se como inspiração para mudanças no contexto organizacional.

\section{ESTRUTURA ORGANIZACIONAL E A FORMAÇÃO EDUCACIONAL DA EQUIPE DE TRABALHO DO INSTITUTO EUVALDO LODI DE MINAS GERAIS}

O Instituto Euvaldo Lodi (IEL), presente em Minas Gerais desde 1969, faz parte do Sistema Federação das Indústrias que atua como interlocutor e promotor da interação entre empresas e centros de conhecimento em todo o Estado. Seu objetivo é transformar investimentos em conhecimento aplicado para as empresas da cadeia produtiva industrial mineira, com foco em oportunidades de negócio, aumento da competitividade, inovação e sustentabilidade. Suas ações estão voltadas à promoção da competitividade por meio de soluções em inovação, capacitação, estudos, diagnósticos, inteligência estratégica, estágio empresarial e negócios internacionais. Seus principais parceiros são, dentre outros, o governo - as secretarias e os ministérios -, as universidades públicas e privadas, os órgãos de fomento à pesquisa, os centros tecnológicos, os bancos financiadores de desenvolvimento, o Sistema "S". Tem como principais clientes a micro, a pequena e a média indústria mineira.

O cliente potencial é a média empresa. Mas não se pode deixar de considerar 0 atendimento à micro e à pequena empresa pelos projetos firmados em parceria com o SEBRAE/MG. São projetos regidos por acordos 
legais, tendo envolvimento de recursos financeiros, por estarem em execução e por serem provenientes de editais. Essa parceria tem como foco 0 fortalecimento das empresas e que essas avancem para o porte médio.

\subsection{Estrutura e formação educacional dos colaboradores por gerência}

O IEL/MG está estruturado a partir de seis gerências estratégicas que fornecem produtos e serviços por encomenda e um Núcleo que se encontra na linha de staff e atende as demandas da superintendência. As gerências estão organizadas para ajudar na ampliação da competitividade das indústrias e empresas mineiras e na busca de estreitar as relações entre às universidades, os centros tecnológicos, os órgãos de fomento e às indústrias, é a denominada interação universidade-indústria. Essa interação permite a inserção da pesquisa e da tecnologia no setor produtivo como forma de modernizar as organizações. Ainda, como intento busca promover curso de educação executivo com foco na estratégia e na inovação para negócios empresariais.

Cabe salientar que o Instituto vem passando por reestruturação desde 2011 e para uma melhor compreensão da composição, serão apresentados dados referentes a cada gerência: a estrutura, o objetivo, a formação do grupo de trabalho, as atividades, os principais setores que cada uma atende.

A Gerência de Capacitação Empresarial é a primeira a ser analisada. O seu objetivo é levar capacitação e desenvolvimento para os executivos e empresários da cadeia produtiva industrial com foco em gestão empresarial de forma que esse grupo possa superar metas e conquistar resultados mais expressivos. As capacitações estão divididas em módulos que podem atender as necessidades dos clientes, alguns desses produtos são customizados. São ofertados produtos de treinamento acoplados a serviços de consultoria, o que permite cobrir, com mais eficácia, as deficiências das organizações-clientes. Quanto aos programas customizados, as indústrias são avaliadas in loco, onde são identificadas as necessidades do cliente e, posteriormente, desenvolvidos produtos específicos, como treinamento, consultoria ou algum outro produto de acordo com o problema do momento.

Os cursos e os programas abertos e de pós-graduação são desenvolvidos para ampliar a formação do indivíduo e o de soluções 
empresariais. O foco é ajudar no desenvolvimento da gestão no ambiente organizacional. A gerência tem como intento, contribuir para que às empresas e às indústrias alcancem patamares competitivos e melhores resultados no mercado em que atuam.

Os projetos de capacitação empresarial são prioridades do gabinete da FIEMG e da área de relações sindicais. Esses estão vinculados aos programas da Confederação Nacional das Indústrias (CNI) de apoio aos sindicatos e aos seus coordenadores e presidentes das Federações. A gerência tem trabalhado, também, com os programas de capacitação em parceria com o SESI e SENAI. Resultado dessas parcerias é o projeto Praticar para Crescer que se iniciou com uma turma - piloto - em Uberaba e está programado para ocorrer em Montes Claros e Governador Valadares. Esse projeto de capacitação contempla os módulos de gestão estratégica, o de finanças, o de gestão comercial - mercado, marketing em vendas, processos, produção, inovação, internacionalização e pessoas, possui uma carga horária de 102 horas. Inicialmente, o foco é a micro e a pequena indústria, na tentativa de fortalecer e transformar a pequena indústria em média.

O papel da gerência de Capacitação Empresarial é atentar-se para as necessidades e as demandas originadas dos empresários. Para tal, é preciso de uma gestão flexível que permita que o funcionário tenha condições de captar as necessidades e as demandas do cliente e tenha autonomia no processo de decisão. Para atender o mercado, a gerência conta com uma equipe com boa experiência nas áreas comercial, comunicação e em programas de educação, e está composta da seguinte forma: cinco colaboradores com bacharelado: três indivíduos com formação em administração, sendo um com especialização em educação à distância, um com especialização em finanças e um doutorando em administração; dois indivíduos com formação em psicologia, sendo que um indivíduo possui quatro especializações: em gestão de negócios, em gestão de processos educativos, em gestão e tecnologia da qualidade e em gestão em instituições educacionais; e um tecnólogo em recursos humanos. 
Foi sinalizado que a estrutura de pessoal está trabalhando no limite. Uma forma encontrada para atender as demandas que entram foi à construção de banco de consultores, decisão que tem ajudado a suprir a falta de mão de obra. Cabe ressaltar que a equipe permanente, efetiva, fica responsável pela coordenação e pelo planejamento das atividades.

A segunda gerência, objeto de nossos comentários, é o Centro Internacional de Negócios (CIN). Essa era uma área ligada diretamente à presidência da FIEMG e foi deslocado para o IEL/Minas. Suas funções estão direcionadas para as atividades fins do Instituto e participa de uma rede mais ampla, a Rede CIN que trabalha pela internacionalização de empresas brasileiras. Essa Rede foi implantada pela $\mathrm{CNI}$, que permite a interação entre os Centros Internacionais das demais federações residentes no Brasil e que tem procurado trabalhar em projetos conjuntos especialmente na divulgação, no apoio e na participação em feiras e em missões. É importante ressaltar que os CIN regionais executam, igualmente, estratégias da própria Rede que começou em 2009 e foi até 2011. O planejamento estratégico que vigora foi estruturado com o horizonte de quatro anos, de 2011 a 2015.

Cabe sinalizar que, em determinados programas e ações que são desenvolvidos pela Rede CIN, algumas vezes uma federação lidera 0 processo, outras vezes essa entra como colaboradora de outra. Existe um programa básico de apoio à ação, com as especificações dos produtos e dos serviços principais, que as federações devem seguir. Todas elas estão trabalhando em conjunto na execução da nova estratégia, definindo o portfólio mínimo de produto na área de inteligência comercial que a Rede deve ofertar. Cada uma dessas federações deve seguir as diretrizes básicas propostas por essa rede, mas é livre para seguir as diretrizes internas da casa. A liberdade está em fazer mais do que foi solicitado pela Rede e atender as diretrizes definidas pelo IEL/MG e pela FIEMG.

A gerência está estruturada a partir de cinco subáreas: a primeira subárea - inteligência comercial - disponibiliza informações estratégicas sobre os principais mercados mundiais, com estatísticas, legislação, oportunidades comerciais, prestadores de serviços. Segunda subárea - promoção comercial - 
realiza eventos em Minas e no exterior, para promover o incremento de negócios e a absorção de tecnologias, através de missões empresariais, encontros de negócios e participação em feiras internacionais. A terceira subárea - capacitação de curta duração - produto da Rede CIN, promove programas de aprimoramento e reciclagem técnico-gerencial em comércio exterior e cursos de curta duração. A quarta subárea - desenvolvimento de negócios - capta oportunidade de negócio. A quinta subárea - cooperação internacional - cuida dos protocolos de intenção, acordos, convênios com as instituições internacionais.

Tem como objetivo apoiar a indústria mineira na exportação, na certificação de produtos preparando o empresário para as missões internacionais. De forma a cumprir o objetivo, acompanha toda legislação de comércio exterior no Brasil e de comércio internacional. Os setores de alimento, moda, bijuteria, joalheria e construção civil (mármore, granito, revestimento, e piso) são os principais clientes. Para atender esses setores a gerência conta com uma equipe de profissionais com formação em comércio exterior, relações internacionais, economistas e administradores, sendo cinco estagiários, três indivíduos com ensino médio completo, três indivíduos com bacharelado, cinco indivíduos com especialização e quatro indivíduos com mestrado.

A terceira gerência em foco - Gerência de Estudos Econômicos - tem uma amplitude de ações grandes e conta com uma equipe homogênea. Essa gerência tem a função de monitorar e acompanhar o desempenho da indústria de Minas Gerais através de pesquisa de campo. Para a obtenção dos dados, trabalha-se com uma amostragem de aproximadamente 300 indústrias. Essa amostragem, de forma geral, permite a validade estatística da transformação extrativa e de alguns outros setores, como têxtil, alimentos, bebidas, material de transportes, siderurgia. A pesquisa conta com a participação, apoio e parceria da $\mathrm{CNI}$, em que outras federações fazem o mesmo estudo, permitindo a geração de indicadores em nível nacional e estadual. Para o tratamento dos dados usam-se softwares, sistemas de informações e metodologias comuns a 
todas as federações. Para o entrevistado 04 "[...] é a única pesquisa que vai além da pesquisa do Instituto Brasileiro de Geografia e Estatística - IBGE [...]".

Os dados provenientes dessa atividade completam os disponíveis pelo IBGE, subsidiando o governo e os próprios setores industriais com um mapa de informações mais detalhado. Também, permitem avaliar o andamento do desempenho da indústria no Brasil e nos estados e que poderão contribuir para a definição de ações efetivas em favor ao desenvolvimento local e nacional.

A gerência realiza, em campo, uma atividade denominada sondagem industrial. É uma pesquisa que não tem a preocupação com a amostragem estatística, já que ela pretende captar a percepção dos empresários em relação a determinados temas, seja em relação à própria produção, seja em relação à situação financeira da empresa. Busca-se identificar quais são os principais problemas que a empresa enfrenta e sua expectativa para os próximos seis meses. Ela é realizada mensalmente e é de âmbito nacional e estadual e com os dados gera o Índice de Confiança do Empresário Industrial. De forma a melhorar a amostragem, a gerência está buscando parceria com algumas universidades mineiras para levantamento dos dados. Ao aumentar a amostra é possível fazer a pesquisa aberta dos três dígitos da Classificação Nacional de Atividades Econômicas (CNAE) do IBGE. Isto quer dizer que ao invés de falar que a indústria de alimentos em Minas já cresceu ou caiu tantos \% ao ano, ou em determinado mês, pode-se dizer que na indústria de laticínio aconteceu à variação $X$.

Compondo o quadro de atividades dessa gerência, tem-se a área de desenvolvimento de estudos de competitividade e análise de setores econômicos. Essa área busca identificar as necessidades provenientes dos sindicatos que representam os setores industriais, por estarem envolvidos nas questões do dia a dia da indústria, do empresário. Para isto é preciso que as relações sejam estreitas, em que todos trabalhem na elaboração de estudos relacionados ao setor, na análise de determinado segmento, levantando as oportunidades, determinando os riscos que existem dentro dos subsetores e dos segmentos que estão ali representados. 
É evidente que as funções da gerência estão voltadas para atender o IEL/MG e a FIEMG como atividade meio, mas, ao atender o mercado, suas atividades são fins. É a única gerência no IEL/MG que atende proporcionalmente tanto o ambiente organizacional interno quanto o externo a indústria. O próprio IEL é um cliente que recebe informações sobre economia industrial.

Para o desenvolvimento das atividades a gerência está estruturada a partir de três núcleos o de pesquisa, o de estudos macroeconômicos e o de setorial. Sua equipe é composta por dez funcionários com bacharelado em economia, sendo sete indivíduos com especialização e três com mestrado; um indivíduo com formação em sociologia e com mestrado em economia setorial; um indivíduo com nível médio e dois estagiários, totalizando quatorze colaboradores.

Outra gerência que compõe a estrutura do IEL/MG - a Gerência de Estágio Empresarial - é responsável por inserir no mercado de trabalho estudantes universitários de todas as áreas do conhecimento que possam atender as indústrias mineiras. Foi o primeiro serviço oferecido pelo IEL/MG e, até hoje, continua como um de seus principais produtos. O objetivo é encurtar a distância entre as escolas, as universidades, os estudantes e as empresas através de processo de seleção e recrutamento de estagiário. Suas ações estão voltadas para as atividades fins desse Instituto.

A gerência, cujo principal cliente é o setor de serviços, tem baixa atuação no setor industrial. Há quase três mil estagiários ativos inseridos no mercado, e durante o ano 2013 a gerência inseriu sete mil estagiários, mas a rotatividade é muito grande. Destes três mil, $20 \%$ estão na indústria, o restante dos $80 \%$ estão na área de serviços. Do universo de $80 \%$, a maior parte corresponde às agências bancárias. Como o mercado nacional está muito aquecido, os estagiários buscam novas oportunidades com muita facilidade, o que torna esse mercado muito volátil. Perguntado por que a demanda por parte das indústrias é tão pequena, o entrevistado 06 responde: "[...] a indústria, ainda, é muito resistente em receber estagiários. Tenho feito reuniões 
frequentes com os agentes de vendas na busca de uma estratégia para minimizar essa lacuna [...]".

Percebe-se o dispêndio de esforço na busca de estreitar as relações com as indústrias e em diminuir as resistências. A equipe de vendas tem dificuldade em adentrar nas indústrias menores, residentes na região do Cinco, área industrial da cidade de Contagem, região metropolitana de Belo Horizonte. O entrevistado 06 relata, "[...] o que se observa que elas não têm o hábito e a cultura de contratar estagiário, o que torna muito difícil aumentar a amostragem de $20 \%$ [...]". Enquanto as grandes empresas estão abertas para a contratação de estagiários, às micro, pequena e média indústria apresentam uma forte resistência em recebê-los. Talvez uma forma de solucionar esse problema seja aproximando e montando parcerias, e até programas, com os sindicatos que representam os setores industriais.

Afirma-se que essa gerência é a única que consegue se auto sustentar devido ao volume de serviço e produtos diversificados. Seu portfólio é customizado de acordo com as necessidades do cliente. $\mathrm{O}$ entrevistado 06 sinalizou que "Com essa forma de trabalho, o cliente paga por aquilo que de fato the interessa. $O$ tempo no atendimento se tornou menor e o desgaste do candidato é minimizado, diminuindo as idas e as vindas ao local das provas [...]". Com o atendimento customizado, a gerência passou de uma receita $X$ para uma receita $\mathrm{Y}$, muito maior. Conforme a colocação do entrevistado 06 "[...] voltar o foco exclusivamente para a indústria, perderemos essa capacidade [...]". Todas as áreas no IEL/MG são cobradas pela auto sustentabilidade, mas não conseguem se manter por conta própria.

A gerência está estruturada em três subáreas: recrutamento, seleção e gestão administrativa. Compondo essa estrutura têm-se trinta e seis colaboradores com as seguintes formações educacionais. Doze colaboradores com nível médio completo, sendo que seis indivíduos cursam psicologia e três cursam administração; quatorze colaboradores com bacharelado, sendo que seis indivíduos possuem formação em administração, destes, três com especialização em gestão estratégica de negócios, em gestão de marketing, em controladoria e auditória, um indivíduo com formação em direito, um 
indivíduo com formação em relações pública e com especialização em marketing, três indivíduos com formação em psicologia, dois indivíduos com formação em jornalismo, sendo que um possui especialização em gestão de pessoas, um indivíduo com formação em letras e com especialização em gestão empresarial; seis estagiários, sendo três em administração, um em psicologia e dois em relações públicas.

O Instituto conta, além disso, com a Gerência de Inteligência Estratégica, que atua como uma antena para os setores e as cadeias produtivas de Minas Gerais, oferecendo produtos informacionais como boletins, relatórios, alertas e estudos setoriais. Esses documentos sinalizam as oportunidades e ameaças relacionadas ao mercado em que às empresas e às indústrias atuam.

A gerência está estruturada em três subáreas: núcleo de inteligência competitiva; núcleo de gestão do conhecimento; e rede tecnológica. Seu corpo de colaboradores está assim distribuído por formação educacional. Sete colaboradores com bacharelado: dois indivíduos com formação em engenharia elétrica, sendo que um possui mestrado em ciências da computação e um possui especialização em gestão de finanças e em gestão de projetos, um indivíduo com formação em jornalismo e com mestrado em ciência da informação, um indivíduo com formação em psicologia e com especialização em relações internacionais, um indivíduo com formação em análise de sistemas e com especialização em gestão empresarial e em gestão estratégica da inovação, um indivíduo com formação em química e com mestrado em engenharia metalúrgica, um indivíduo com formação em administração e com especialização em administração estratégica; dois consultores, sendo um indivíduo com formação em engenharia elétrica, com especialização em gestão empresarial e em gestão de comércio e um indivíduo com formação em veterinária e com pós-doutorado; onze bolsistas: dois indivíduos com formação em biologia, dois indivíduo com formação em jornalismo, sendo um com especialização em propriedade intelectual, dois indivíduo com formação em administração, dois indivíduos com formação em Ciências atuariais, um indivíduo com formação em engenharia de bioenergia, um indivíduo com 
formação e mestrado em engenharia de produção, um indivíduo com formação em design; três estagiários, sendo um em biblioteconomia e dois em administração.

Tem como principais setores como clientes o de Petróleo e gás, o de biotecnologia, o de energia e o de aeroespacial. Setores extremamente dinâmicos, que precisam de informações com alto valor agregado, confiáveis e atualizadas. Para atender as necessidades desses clientes a gerência conta com quatro Núcleos de Inteligência Competitiva (NIC) que disseminam informações estratégicas analisadas por especialistas, mantendo os empresários atualizados sobre as oportunidades e as ameaças do mercado. Suas ações estão voltadas para atender as atividades fins do Instituto.

Os NIC surgiram em um ambiente de cooperação para a produção do conhecimento em atendimento às várias questões formuladas pelas cadeias produtivas. Sua criação foi em 2006, e o intento era mobilizar as competências e os atores em vários níveis das cadeias de forma a estimular a competitividade das empresas de micro, de pequeno e de médio porte. As ações dos NIC são inerentes à execução dos negócios dos clientes, comercializa também produtos e serviços tais como consultorias, planos de negócios, treinamentos e serviços técnicos provenientes de estudos prospectivos e análise de tendências. A aplicabilidade dos produtos e serviços é tratada em três níveis básicos: as empresas propriamente ditas, a cadeia produtiva ou o arranjo produtivo local (APL) e o setor industrial.

A Rede Tecnológica de Minas Gerais (RETEC/MG) faz parte da estrutura dessa gerência e contribui com as informações provenientes das demandas da indústria e das levantadas em projetos e serviços tecnológicos apoiados pelo AMITEC ${ }^{1}$. A gerência tem como papel, também, o desenvolvimento, o acompanhamento, a implementação da gestão da informação no IEL/MG e o apoio às gerências nessa gestão.

\footnotetext{
${ }^{1}$ AMITEC é um programa criado pelo Instituto Euvaldo Lodi/MG, em parceria com a Fundação de Amparo à Pesquisa do Estado de Minas Gerais (FAPEMIG) e o SEBRAE/MG, tendo como principal objetivo estimular a melhoria e a inovação tecnológica das empresas de Minas Gerais, através de subsídio financeiro.
} 
Essa gerência tem um campo vasto de atuação por ter como matériaprima a informação. Cabe ressaltar que, ao adotar os princípios da gestão da informação, (re)conhecendo as necessidades dos clientes, essa gestão poderá ajudar para que a indústria se posicione no mercado e atue com valor agregado e de forma competitiva.

Compondo o quadro de gerências do Instituto, tem-se a de inovação, denominada como Núcleo de Apoio à Inovação (NAI). Essa gerência assessora e orienta as empresas na sua busca pela competitividade através da inovação. Suas ações estão voltadas para as atividades fins do Instituto. Atuando com o conceito de inovação em sua dimensão mais ampla e considerando a tecnologia, o produto, o processo, o modelo de negócio, o método organizacional e o mercado, a gerência procura incentivar e demonstrar às empresas que a inovação pode estar ao seu alcance independentemente do porte ou do setor de atuação e que, em um mercado cada dia mais complexo, torna-se um meio fundamental para sua sobrevivência.

Então, fazer com que às micro, pequena e média indústria entendam que é preciso investir em formação e em qualificação tem sido um impasse para o desenvolvimento do setor industrial mineiro. Para contribuir com os avanços em Minas e em outras federações, a CNI iniciou, em 2009, com a criação do Núcleo da Mobilização Empresarial pela Inovação (MEI), um trabalho de articulação que estimule a liderança empresarial e os parceiros dos setores a investirem em produtos e processos e que apoia a implementação de projetos inovadores. $\mathrm{O}$ objetivo da $\mathrm{CNI}$ é conseguir duplicar o número de empresas inovadoras em todo o país, em um período de quatro anos.

O núcleo mineiro é aportado pelos convênios com instituições parceiras, como CNI, FINEP e SEBRAE. Oferece às empresas soluções integradas em gestão da inovação, tendo como suporte a capacitação, a elaboração de planos de gestão da inovação nas empresas e assessoria para concepção de projetos de inovação, por meio da formação de competências no ambiente empresarial. Para a aprovação e aceite no programa, o empresário precisa se candidatar no mínimo em uma das categorias: apresentação do plano de inovação que define detalhadamente os objetivos, as metas e os passos para a 
empresa atingir resultados inovadores, considerando quais os projetos devem ser implantados para se atingir o objetivo geral do plano.

Dessa forma, os consultores auxiliam na organização do potencial competitivo e inovador e identificam os projetos a serem implementados. Esses projetos detalham o que vai ser feito, porque deve ser feito, quem vai fazer, quando serão feitos, onde serão feitos e quanto vão custar, sendo formatados conforme as diretrizes dos principais órgãos de fomento e financiamento à inovação no Brasil. Posteriormente, a empresa poderá apresentar os projetos de inovação para obter recursos em tais órgãos. A seleção das empresas depende da descrição da perspectiva de futuro, dos potenciais projetos de inovação e do grau de envolvimento da liderança empresarial, além da motivação para participar do projeto, esses fatores são fundamentais e considerados.

A gerência tem uma atuação significativa na orientação às indústrias sobre as questões da propriedade intelectual. $O$ foco é proteger todo 0 conhecimento gerado no Estado, transformando-o em produtos e serviços que estarão à disposição da sociedade através da comercialização. $O$ conceito de inovação adotado está em conformidade com o definido pela World Intellectual Property Organization (WIPO). Para atender aos parâmetros determinados nas legislações, é preciso que a gerência tenha um quadro de colaboradores atualizados e que acompanhe as mudanças ocorridas na legislação e nos acordos internacionais. Seu papel, também, é auxiliar as indústrias no tratamento de todas as questões relacionadas à propriedade industrial, praticando ações de sensibilização, esclarecimentos, consultorias e prestações de serviços ao empresário. Além disso, oferece desde informações básicas sobre procedimentos relacionados à propriedade intelectual e taxas oficiais do Instituto Nacional da Propriedade Industrial (INPI) até informação tecnológica e estratégica para proteção de seus ativos intangíveis.

Assim, as parcerias tecnológicas são fundamentais para o bom andamento dos projetos tecnológicos. É visível que as organizações bemsucedidas são competitivas porque inovam continuamente, sendo 0 
desenvolvimento tecnológico recurso primordial para nova economia que tem seu alicerce no conhecimento e no processo de aprendizado.

É importante destacar que todo processo de inovação requer criatividade, aprendizagem e conhecimento. O indivíduo é o cerne de toda a incorporação de inovação em um segmento ou setor industrial. Toda indústria competitiva é aquela que incorpora tecnologia em seus processos de produção e de gestão, sejam tecnologias dominadas, adquiridas ou desenvolvidas especificamente para o seu negócio, em que o indivíduo é a mola propulsora de vastas atividades de pesquisa e de desenvolvimento (P\&D). No campo da inovação, as parcerias entre institutos de pesquisa, universidades, órgãos de fomento à pesquisa são fundamentais. Cabe ressaltar que, quando se fala em inovação, não significa apenas referir-se a propostas complexas e que requerem investimentos vultosos em P\&D, mas também se deve considerar as pequenas inovações de melhoria em processos e produtos, tão presentes no dia atual, e atentar nelas.

A gerência está estruturada em três subáreas: gestão de projetos de inovação, núcleo da mobilização empresarial e propriedade intelectual, que atende principalmente os setores eletroeletrônicos, tecnologia da informação, biotecnologia. Sua equipe de trabalho está formada por cinco bacharéis: um indivíduo com formação em economia e com especialização em gestão de projetos e mestrando em biofarmácia; um indivíduo com formação em jornalismo e com especialização em gestão estratégica da informação e mestranda em gestão ambiental, um indivíduo com formação em direito e com especialização em conhecimentos tradicionais e propriedade intelectual, um indivíduo com formação em engenharia de produção e mestre em engenharia de produção e um indivíduo com formação em administração e com especialização em gestão de projetos; e cinco bolsistas: dois indivíduos com formação em direito, um com especialização em propriedade intelectual, dois indivíduos com formação em economia e um indivíduo com formação em jornalismo.

Dando suporte principalmente à Superintendência e às gerências, o IEL conta com o Núcleo de Apoio à Gestão. Esse surge em 2007 com o intuito de 
desenvolver, de controlar e de supervisionar as atividades administrativas e financeiras, atuando nas atividades de apoio inerentes a convênios e projetos, ao controle orçamentário e planejamento. Está estruturada em duas subáreas: prestação de contas e orçamento e gestão de projetos e bolsa. Sua função é atender as necessidades do IEL/MG e Sistema FIEMG, através de atividades meio. A área conta com uma equipe com boa formação, mas apenas dois colaboradores possuem especialização lato sensu, assim composta: cinco bacharéis em administração, dois com especialização em gestão de projetos e um com gestão de finanças e controladoria; e quatro estagiários que cursam administração.

Talvez por ser atividades de rotina e com pouca inovação nos processos administrativos, o que se pode observar é que as atividades meios não são contempladas com pessoal de nível de formação mais elevado. As atividades fins contam com uma equipe com boa experiência e formação educacional no Instituto.

Foi possível observar que a estrutura organizacional do IEL/MG e os seus processos de decisão podem ser considerados hierárquicos e, em alguns momentos das entrevistas, percebeu-se certa centralização das informações e do poder. A estrutura do Instituto está em parte consolidada em projetos, como a Gerência de Inovação, de Inteligência Estratégica e o Centro Internacional de Negócios e, também, funcional. No passado, fechava-se um projeto, procuravase um parceiro - um ministério, uma secretaria -, montava-se uma equipe e executavam-se as etapas definidas no projeto. Hoje, procura-se definir as atividades, as funções e as ações que tenham uma continuidade, como o monitoramento do setor industrial. A estrutura fixa visa manter as atividades operacionais e do dia a dia. A outra estrutura, a de projetos, é flexível e envolve profissionais multidisciplinares. Os membros que compõem a equipe de projetos são, na maior parte, bolsistas ou consultores - uma boa parcela com formação nos níveis de mestrado e doutorado -, sendo esses responsáveis pela execução e coordenação dos projetos.

Assim, para uma melhor compreensão de como está composta a equipe de trabalho do IEL/MG, apresenta-se na tabela 1 um condensado por 
percentagem de indivíduos referente ao nível de formação educacional e ocupação por gerência. Do universo de 114 colaboradores, 78 possuem nível superior - bacharéis e tecnólogo; 1 com doutorado, 14 com mestrado e 25 com especialização (lato sensu); 20 estagiários; e 16 com ensino médio completo. Observa-se que é difícil encontrar, em uma estrutura organizacional, um corpo administrativo e técnico com boa qualificação e experiência, sendo que $68 \%$ dos indivíduos possuem nível superior completo. Cabe ressaltar que, no universo de indivíduos com ensino médio $75 \%$ deles estão cursando graduação em diversas áreas do conhecimento.

Tabela 1: Relação percentual de formação educacional por gerência

\begin{tabular}{c|c|c|c|c|c|c}
\hline Gerência & Nível Médio & Estagiário & Tecnólogo & Bacharéis & Total & Percentagem \\
\hline Capacitação Empresarial & & & 1 & 5 & 6 & $5 \%$ \\
\hline $\begin{array}{c}\text { Centro Internacional de } \\
\text { Negócio }\end{array}$ & 3 & 5 & & 12 & 20 & $18 \%$ \\
\hline $\begin{array}{c}\text { Estágio Empresarial } \\
\text { Estudos Econômicos }\end{array}$ & 12 & 6 & & 14 & 32 & $28 \%$ \\
\hline $\begin{array}{c}\text { Inteligência Estratégica } \\
\text { Núcleo de Apoio à } \\
\text { Gestão }\end{array}$ & 1 & 2 & & 11 & 14 & $12 \%$ \\
\hline $\begin{array}{c}\text { Núcleo Apoio à Inovação } \\
\text { Total }\end{array}$ & 16 & 4 & & 20 & 23 & $20 \%$ \\
\hline Percentagem & $14 \%$ & $18 \%$ & $1 \%$ & $67 \%$ & $100 \%$ & 10 \\
\hline
\end{tabular}

Fonte: Dados da pesquisa e elaboração da autora, 2013.

Frisa-se que o Instituto tem uma mão de obra com idade média de 30 anos, um grupo jovem e em formação. A Gerência de Estágio Empresarial é a que possui o maior número de indivíduos com nível médio e, também, o maior número de estagiários. Por outro lado, a Gerência de Inteligência Estratégica é a que possui o maior número de indivíduos com bacharelado. Observa-se que quanto maior a atuação em mercados complexos, dinâmicos e vulneráveis, maior a exigência por serviços e produtos com valor agregada, e indivíduos com formação multidisciplinares, com alto nível de formação educacional. 


\section{CONSIDERAÇÕES FINAIS}

As estruturas organizacionais quando alinhadas aos objetivos e às estratégias da organização facilitam a compreensão de atuação dos colaboradores, onde a organização deseja chegar e qual a capacidade de participação no mercado, seja como seguidora, seja como inovadora, ou líder. Assim, a estrutura organizacional do IEL/MG está em consonância com sua meta.

As áreas que têm com mais clareza o papel dentro do Instituto são as gerências de Inteligência Estratégica, de Inovação e de Estágio Empresarial por fazerem parte do ambiente organizacional há mais tempo. Quanto à gerência de Estudos Economia, percebeu-se pela fala do entrevistado 04, que ela está solta na estrutura do IEL e o melhor vínculo seria próximo da presidência da FIEMG, até mesmo por suas atividades estarem diretamente relacionadas às necessidades e às demandas do nível estratégico da Federação. A gerência de Capacitação Empresarial não tem com clareza o que será a sua área, quais os produtos e os serviços que serão o portfólio, e quais os perfis profissionais que serão necessários para a execução das atividades por ser a área mais nova no Instituto. A gerência Centro Internacional de Negócios era uma área que reportava também ao nível estratégico da FIEMG. Para o entrevistado 03, não importa onde sua gerência esteja hierarquicamente subordinada, é preciso de infraestrutura que facilitem a execução de suas atividades e que o cliente interno ou externo tenham suas necessidades e demandas atendidas.

Observa-se que a gerência que possui um quadro de colaboradores com menor formação educacional é a que se mantém, é autossuficiente financeiramente. A gerência de estágio empresarial vende produtos e serviços a um número grande de organizações e o seu trabalho tem reconhecimento no mercado. Quanto às outras gerências, essas são subsidiadas por recursos do Sistema "S" ou por recursos provenientes de editais ofertados pelo governo, estão se estruturando para atingir a auto sustentação, mas muito tem que ser feito para se posicionarem de forma competitiva no mercado. 
Vê-se uma estrutura organizacional fundamentada nos moldes tradicionais da administração, onde o processo de decisão é centralizado e a informação permanece no domínio de poucos. O indivíduo para participar do movimento da organização precisa corresponder ao estabelecido em normas, procedimentos e manuais. Esse tem pouca participação e autonomia nas decisões, sua formação educacional, quando financiada com recursos da Federação, está estritamente relacionada com as atividades que exerce e no que a gerência deve gerar como resultado. O grupo está em um nível ainda de amadurecimento e com uma visão de serviço burocrático, operacional. Não está relacionado à formação do grupo, que é constituído de graduados e pósgraduados em nível até de mestrado, tecnicamente são bons. Os treinamentos estão voltados para a linha de "treinamentos Taylor" como colocado pelo entrevistado 04.

A composição física passou por mudanças, mas a cultura traz fortes traços do passado. Para que esse quadro mude é preciso que se pense na manifestação de intencionalidade da organização, em que as relações de trabalho sustentadas com a equipe, a colaboração de todos e entre todos, com troca e compartilhamento de informação e com a harmonia passem a ser estratégicas. Assim, todos os envolvidos - organização e atores - podem sobreviver ao cenário cada dia mais acirrado e competitivo.

Por fim, toda estrutura organizacional é formada a partir de uma cultura pré-estabelecida, que está formada pelo crescente simbolismo nos negócios, na sociedade e na organização, à qual o indivíduo empresta sua identidade, sua privacidade e seus desejos. Essa estrutura pode ser contemplada com os princípios de departamentalização por projetos e função.

Os dados revelaram que a formação do indivíduo acompanha a necessidade interna e externa da organização, e, consequentemente, a estrutura organizacional. Deste modo considera-se que as organizações são representadas por empresas, departamentos de empresas, indústrias, grupos ou qualquer arranjo humano em que a manipulação simbólica (Wood Jr., 2000) seja o elemento central do jogo gerencial. Nelas, os líderes e liderados fazem extensivo uso da retórica e das metáforas e procuram manipular a fluidez dos 
símbolos e modificar a estrutura organizacional de acordo com as exigências percebidas.

A organização é considerada como aquela que dispõe de símbolos visíveis, como manifestações físicas e indicadores da vida organizacional. São esses símbolos que podem ser experimentados com os sentidos e usados pelos indivíduos para fazer sentido. Quanto ao indivíduo, esse é o ser criador, pensante e condutor da dinâmica organizacional e sem ele é impossível a existência da estrutura organizacional e social.

\section{REFERÊNCIAS}

ARAUJO, L. C. G. Organização, sistemas e métodos e as tecnologias de gestão organizacional: arquitetura organizacional, benchmarking, empowerment, gestão pela qualidade total, reengenharia. 4. ed. 3. reimpr. São Paulo: atlas, 2009.

COELHO, A.; COELHO, F. As debilidades estruturais das organizações: 0 exemplo ibérico. Revista de Administração Contemporânea. ed. esp, p. 143-164. 2003.

DELUIZ, N. O modelo das competências profissionais no mundo do trabalho e na educação: implicações para o currículo. Boletim Técnico do SENAC. Rio de Janeiro, v.2, n.3, p.12-25, dez. 2001. Disponível em: http://www.senac.br/INFORMATIVO/BTS/273/boltec273b.htm. Acessado em 11 de julho de 2014.

MACHADO-DA-SILVA, C. L.; FONSECA, V. S. Estruturação da estrutura organizacional: o caso de uma empresa familiar. Rev. Adm. Contemp, Curitiba, v.14, n. Especial, set. 2010. Disponível em: http://dx.doi.org/10.1590/S1415-65552010000600002. Acessado em 5 de jun. 2014.

O'DWYER, G.; MATTOS, R. A. Teoria da estruturação de Giddens e os estudos de práticas avaliativas. Rio de Janeiro, Physis, v. 20, n. 2, 2010.

OLIVEIRA, D. P. R. Sistemas, organização e métodos: uma abordagem gerencial. 18. ed. São Paulo: Atlas. 2009.

RODRIGUES, A. L. Tensões entre econômico e social: uma proposta de análise à luz da teoria da estruturação. Revista de Administração de Empresa, v. 48, n. 2, p. 37-50, abr/jun. 2008. 
WOOD JR, T. Organizações de simbolismo intensivo. Revista de

Administração de Empresas, v. 40, n.1, p.20-28, jan/mar. 2000.

YIN, R. K. Estudo de caso: planejamento e métodos. 3. ed. Porto Alegre:

Bookman, 2005.

\title{
Title
}

Organizational structure and educational training of workers of Institute Euvaldo Lodi of Minas Gerais

\begin{abstract}
:
Introduction: The market increasingly competitive suffering with the great transformations has demanded the setting organizations in their internal structures, as well as better training and education worker training, stimulating the reflection and creativity. These changes force organizations to act on increasing production and offering more effective results that enable more competitive and innovative structures.

Objective: This article aims to know the organizational structure of Euvaldo Lodi Institute of Minas Gerais (IEL / MG) and the level of educational training of their workers.

Methodology: Regarding the methodological parameter used the case study, qualitative approach and the adoption of semi-structured interview. The sample comprised $100 \%$ of managers headquartered in the city of Belo Horizonte and a coordinator in the staff of the Institute line. The meetings were scheduling in advance and integrally recorded and transcribed interviews.

Results: As the main result, the Institute has managers who are organized to assist in the expansion of competitiveness of Minas Gerais industry and seeking strengthen relations between technological actors. We observed that the higher the performance in complex, dynamic and vulnerable markets, the greater the requirement from services and products with added value, and individuals with multidisciplinary training, high level of educational training.

Conclusions: It is concluded that the organizational structure of IEL / MG is in consonance with its goal. The strongest areas are the Strategic Intelligence managements of Innovation and Business Stage for being part of the organizational environment longer. The Economics Studies management is loose in the structure of IEL and the best bond would be the next president of FIEMG; the management of Corporate Training has not clearly what will be its area, what products and services which will be the portfolio and what professional profiles that will be needed to carry out the activities for being the newest area in the Institute; International Centre for the management of business no matter where management is hierarchically subordinate, it is necessary infrastructure to facilitate the implementation of activities and the internal or external customer has needs and demands met.
\end{abstract}

Keywords: Educational background. Organization. Organizational structure.

\section{Titulo}

Estructura organizacional y capacitación de la educación de los trabajadores de lo Instituto Euvaldo Lodi de Minas Gerais 


\section{Resumen:}

Introducción: El mercado cada vez más competitivo, que sufre con los grandes cambios, ha requerido ajustes de las organizaciones en sus estructuras internas, así como una mejor formación y capacitación del trabajador educación, estimulando la reflexión y la creatividad. Estos cambios obligan a las organizaciones a actuar en el aumento de la producción y ofreciendo resultados más eficaces que permiten a estructuras más competitivas e innovadoras.

Objetivo: Este artículo tiene como objetivo conocer la estructura organizativa del Instituto Euvaldo Lodi de Minas Gerais (IEL / MG) y el nivel de formación educativa de sus trabajadores.

Metodología: Cuanto al parámetro metodológico fue utilizado el estudio de caso, el enfoque cualitativo y la adopción de la entrevista semi-estructurada. La muestra fue de $100 \%$ de los directivos con sede en la ciudad de Belo Horizonte y un coordinador de la línea de staff del Instituto. Las reuniones fueron programadas antelación y entrevistas totalmente grabadas y transcritas.

Resultados: Como resultado principal, Instituto dispone de gerencias que se organizan para ayudar en la expansión de la competitividad de la industria minera y que buscan fortalecer las relaciones entre los agentes tecnológicos. Se observó que cuanto mayor la actuación en mercados complejos, dinámicos y vulnerables, mayor es la exigencia de servicios y productos con valor agregado, y personas con formación multidisciplinar y alto nivel de formación educativa.

Conclusiones: Se concluye que la estructura organizacional IEL / MG está en consonancia con su meta. Las áreas más fuertes son las gerencias de Inteligencia Estratégica, de Innovación y de Estigio Empresarial por ser parte del ambiente organizacional hace más tiempo. La gerencia de Estudios de Economía está suelto en la estructura de IEL y el mejor vínculo sería el próximo presidente de FIEMG; la gerencia de la Capacitación Empresarial no tiene claro lo que será su área, cuales son productos y servicios que será la cartera y cuales perfiles profesionales que serán necesarios para realización de las actividades por ser la área más nueva en el Instituto; para la gerencia del Centro Internacional de Negocios no importa donde la gestión está jerárquicamente subordinado, es necesario de infraestructura que facilitan la implementación de actividades y que el cliente interno o externo tiene necesidades y demandas respondida.

Palabras clave: Formación educacional. Organización. Estructura de la organización.

Recebido: 10.03.2017

Aceito: 10.11 .2017 